\title{
Mikania glomerata Spreng: Desenvolvimento de um produto fitoterápico
}

\author{
Leandro Rocha, * Elisabeth M. A. Lucio, Hildegardo S. França, \\ Nikolai Sharapin (in memoriam) ${ }^{\dagger}$

\begin{abstract}
Laboratório de Tecnologia de Produtos Naturais, Faculdade de Farmácia, Universidade Federal Fluminense, Rua Mário Viana, 523, Santa Rosa, 24241-002 Niterói-RJ, Brasil
\end{abstract}

\begin{abstract}
RESUMO: Apesar da atividade farmacológica de Mikania glomerata Spreng. ser conhecida desde longa data, existem poucos estudos visando a preparação de produtos padronizados que garantam uma produção uniforme, doses eficazes e estabilidade. Nesse trabalho, foram realizados ensaios objetivando a otimização do processo extrativo; tratamento da droga vegetal para o preparo de tinturas; determinação da melhor forma de estocagem e otimização da preparação da forma farmacêutica (xarope).
\end{abstract}

Unitermos: Mikania glomerata, Asteraceae, tecnologia de produção, fitoterapia.

\begin{abstract}
Mikania glomerata Spreng: development of a herbal medicine”. Although the pharmacological activity of Mikania glomerata Spreng. has been well known for a long time, there are a few studies concerning the elaboration of phytopharmaceutical products that assure an uniform preparation, effective doses and stability. In this work, tests with the objective of the optimization of the extraction process were performed; treatment of the plant drug for preparation of tinctures; determination of the adequate form of storage and the optimization of the preparation of the pharmaceutical form (syrup).
\end{abstract}

Keywords: Mikania glomerata, Asteraceae, technology of preparation, phytotherapy.

\section{INTRODUÇÃO}

Mikania glomerata pertence à família Asteracea sendo conhecida popularmente pelo nome de "guaco». Desde longa data a Mikania glomerata tem sido utilizada popularmente nos casos de asma, broquite e como adjuvante no combate à tosse (Teske \& Trentini, 1997; Silva et al., 2006; Soares et al., 2006; Agra et al., 2008). Um exemplo de sua importância foi a sua inclusão entre as plantas que compuseram a primeira edição da Farmacopéia Brasileira, já em 1929 (Dias da Silva, 1929; Brandão et al., 2006; 2008). Outros trabalhos mostraram sua atividade anti-alergênica (Fierro et al., 1999), antimicrobiana (Pessini et al., 2003; Amaral et al., 2003; Santos et al., 2003; Duarte et al., 2004), além de atividade analgésica (Ruppelt et al., 1991), anti-inflamatória (Falcão et al., 2005), antioxidante (Vicentino et al., 2007) e anti diarréica (Salgado et al., 2005). O estudo fitoquímico dessa espécie resultou no isolamento dos ácidos ent-caur16(17)-em-19-óico, ent-15- $\beta$-isobutiloxicaur-16(17)em-19-óico, ent-15- $\beta$-benzoioxicaur-16(17)-en-19óico, ent-15- $\beta$-hidroxicaur-16(17)-em-19-óico, ent-17hidroxicaur-15(16)-em-19-óico, o-hidroxicinâmico, além das substâncias estigmasterol, friedelina, $\beta$-sitosterol, lupeol e cumarina (Santos et al., 1996;
Taleb-Contini et al., 2006; Veneziani, 1997). Cumarina, um dos seus principais constituíntes químicos, mostrou ser responsável, pelo menos em parte, pela atividade broncodilatadora da planta através do relaxamento da musculatura lisa (Leite et al., 1992; Soares et al., 1996; Leal et al., 1996). Apesar da comprovação de sua atividade farmacológica, para a obtenção de um produto fitoterápico de qualidade, várias etapas precisam ser desenvolvidas. Entre elas citamos a otimização do processo extrativo, otimização do processo de secagem do material vegetal, verificação do prazo de validade de estocagem, determinação do prazo de validade da tintura, determinação da melhor técnica para a produção da forma farmacêutica final e o desenvolvimento de técnicas de controle de qualidade. Nesse trabalho, são descritos os resultados alcançados com o objetivo de transformar a planta Mikania glomerata em um produto fitoterápico de qualidade, com segurança e eficácia comprovada para o uso seguro pela população.

\section{MATERIAIS E MÉTODOS}

\section{Material vegetal}

Diversas amostras de folhas de Mikania glomerata Sprengel (guaco, Asteraceae), foram colhidas 
em épocas diferentes no município de São José do Vale do Rio Preto, RJ pela botânica Dra. Yara Brito, a quem agradecemos. As amostras foram fornecidas na forma fresca.

\section{Substância de referência}

Para a construção das curvas de calibração para as análises quantitativas foi utilizada cumarina (1,2benzopirona - $\mathrm{C}_{9} \mathrm{H}_{6} \mathrm{O}_{2}$ ), na forma cristalina (Sigma Chemical Company, artigo C4261).

\section{Análise quantitativa}

A quantificação da substância ativa nas amostras foi feita por Cromatografia Líquida de Alta Eficiência CLAE utilizando-se padrão externo de cumarina como referência. Foi construída uma curva de calibração com as concentrações de cumarina de $0,2 \mathrm{mg} / \mathrm{ml}, 0,1 \mathrm{mg} / \mathrm{ml}$ e $0,05 \mathrm{mg} / \mathrm{ml}$. Utilizou-se um aparelho GBC equipado com coluna ODS2, $5 \mu \mathrm{m}, 250 \times 4 \mathrm{~mm}$ e, como fase móvel, um sistema isocrático constituído por mistura acetonitrila/água 30:70 (ambos com 0,05\% de TFA) em 20 minutos com fluxo de $1 \mathrm{ml} / \mathrm{min}$ e detecção UV $280 \mathrm{~nm}$.

\section{Otimização do processo extrativo}

11 amostras de $2 \mathrm{~g}$ de folha de guaco secas à temperatura ambiente e, posteriormente, moídas foram extraídas com misturas etanol:água nas proporções de 0:100, 10:90, 20:80, 30:70, 40:60, 50:50, 60:40, 70:30, 80:20 e 94:6. A extração foi realizada por maceração ativa com $20 \mathrm{ml}$ de solvente num período de 24 horas, com posterior filtração das amostras. Desta forma foram obtidas 11 tinturas, nas diversas graduações alcoólicas. Essas 11 amostras foram analisadas quantitativamente por CLAE utilizando cumarina como padrão externo.

\section{Tratamento da droga para o preparo de fitoterápicos}

O material vegetal fresco foi dividido em 3 frações. Uma fração foi seca em temperatura ambiente por aproximadamente 7 dias (tempo necessário para secagem total); outra fração foi submetida à secagem em estufa a $40{ }^{\circ} \mathrm{C}$ por $48 \mathrm{hs;}$ uma terceira fração foi extraída diretamente da planta fresca. Todas as extrações foram realizadas por maceração ativa num período de 24 horas, na proporção de $10 \%$ em relação ao resíduo seco do vegetal, de forma a se obter uma tintura final com alcoolatura de $70 \%$. Foram realizadas análises quantitativas das 3 tinturas por CLAE, utilizando cumarina como padrão externo.

Determinação da melhor forma de estocagem
Material vegetal seco em estufa a $40{ }^{\circ} \mathrm{C}$ por 48 hs foi dividido em 3 partes; a primeira foi estocada inteira (amostra 1); a segunda foi estocada depois de rasurada (amostra 2) e a terceira parte (droga fresca) foi transformada diretamente em tintura e nessa forma foi estocada (amostra 3). Mensalmente foram realizadas análises quantitativas nessas 3 amostras por HPLC, utilizando-se cumarina como padrão externo. As extrações para quantificação do teor de princípios ativos nas amostras 1 e 2 foram realizadas por maceração ativa num período de 24 horas, na proporção de $10 \%$ em relação ao resíduo seco do vegetal, de forma a se obter uma tintura final com alcoolatura de $70 \%$. A amostra 3, representada pela tintura, foi analisada diretamente.

\section{Preparação da forma farmacêutica final}

2 amostras de $500 \mathrm{ml}$ de xarope foram preparados utilizando-se sacarose (425 g), nipagin (0,9 g), nipazol $(0,1 \mathrm{~g})$ e água destilada $(250 \mathrm{ml})$. Numa das amostras a incorporação da tintura foi feita à temperatura ambiente (adição a frio); em outra amostra a tintura foi incorporada à $80^{\circ} \mathrm{C}$ (adição a quente). Preparou-se o xarope introduzindo $250 \mathrm{ml}$ de água destilada num becher de $1000 \mathrm{ml}$. Adicionou-se em seguida o nipagin e o nipazol, e a mistura foi aquecida a aproximadamente $80{ }^{\circ} \mathrm{C}$, com agitação constante, até a dissolução dos componentes. Adicionou-se então o restante da sacarose, aos poucos, até sua dissolução total. Uma das amostras do xarope foi adicionada, ainda quente, de 50 $\mathrm{ml}$ de tintura a $10 \%$ (adição a quente). Outra amostra foi resfriada a temperatura ambiente e adicionada de $50 \mathrm{ml}$ de tintura a 10\% (adição a frio). À temperatura ambiente, a densidade de ambas as amostras do xarope a $20^{\circ} \mathrm{C}$ era de $1,32 \mathrm{~g} / \mathrm{cm}^{3}$. Para a quantificação do teor em princípio ativo do xarope, extraiu-se $25 \mathrm{ml}$ do xarope com duas porções de $12,5 \mathrm{ml}$ de $\mathrm{CH}_{2} \mathrm{Cl}_{2}$ em funil de separação. Após evaporação cuidadosa sob vácuo, retomou-se em $10 \mathrm{ml}$ de metanol e utilizou-se para análise quantitativa em HPLC.

\section{RESULTADOS}

\section{Otimização do processo extrativo}

Para determinar a proporção de álcool e água na solução extrativa que possibilitasse a extração de teores maiores de cumarina, a amostra vegetal foi extraída com etanol/água nas proporções de 0:100, 10:90, 20:80, 30:70, 40:60, 50:50, 60:40, 70:30, 80:20 e 94:6. Foram utilizadas 11 amostras de $2 \mathrm{~g}$ de folhas de guaco secas resultando em 11 tinturas com teor alcoólico diferente. Abaixo os resultados da quantificação do teor de cumarina nestas amostras estão na Tabela $\mathbf{1}$.

$\begin{aligned} & \text { Determinação da droga para o preparo de } \\ & \text { fitoterápicos }\end{aligned}$
a 
Tabela 1. Concentração de cumarina em amostras de Mikania glomerata extraídas em diferentes alcoolaturas.

\begin{tabular}{c|c|c}
\hline Amostra & Alcoolatura (\%) & Quantificação (mg/ml) \\
\hline 1 & 0 & 0,15 \\
2 & 10 & 0,21 \\
3 & 20 & 0,18 \\
4 & 30 & 0,23 \\
5 & 40 & 0,23 \\
6 & 50 & 0,26 \\
7 & 60 & 0,31 \\
8 & 70 & 0,47 \\
9 & 80 & 0,18 \\
10 & 90 & 0,04 \\
11 & 94 & 0,05 \\
\hline
\end{tabular}

Tabela 2. Concentração de cumarina em tinturas de guaco preparadas com planta fresca, seca à temperatura ambiente e seca em estufa.

\begin{tabular}{l|c}
\hline \multicolumn{1}{c|}{ Produto } & $\begin{array}{c}\text { Quantificação } \\
(\mathrm{mg} / \mathrm{ml})\end{array}$ \\
\hline $\begin{array}{l}\text { Tintura de guaco seco à temperatura } \\
\text { ambiente }\end{array}$ & 0,69 \\
Tintura de guaco seco em estufa & 0,90 \\
Tintura de guaco fresco & 0,69 \\
\hline
\end{tabular}

Tabela 3. Concentração em cumarina em amostras estocadas como planta inteira, planta rasurada e tintura obtida por extração logo após a secagem.

\begin{tabular}{l|c|c|c}
\hline & $\begin{array}{c}\text { Planta seca } \\
\text { inteira. } \\
\text { Quantificação } \\
(\mathrm{mg} / \mathrm{ml})\end{array}$ & $\begin{array}{c}\text { Planta seca } \\
\text { rasurada. } \\
\text { Quantificação } \\
(\mathrm{mg} / \mathrm{ml})\end{array}$ & $\begin{array}{c}\text { Tintura obtida } \\
\text { logo após } \\
\text { secagem } \\
\text { Quantificação } \\
(\mathrm{mg} / \mathrm{ml})\end{array}$ \\
\hline $\begin{array}{l}\text { Primeiro } \\
\text { mês }\end{array}$ & 1,38 & 2,29 & 2,58 \\
$\begin{array}{l}\text { Segundo } \\
\text { mês }\end{array}$ & 1,34 & 1,89 & 2,34 \\
$\begin{array}{l}\text { Terceiro } \\
\text { mês }\end{array}$ & 1,20 & 1,85 & 2,09 \\
$\begin{array}{l}\text { Quarto } \\
\text { mês }\end{array}$ & 0,49 & 0,82 & 2,05 \\
Quinto \\
mês
\end{tabular}

Tabela 4. Concentração em cumarina de xarope de guaco preparado à quente e preparado à frio.

\begin{tabular}{l|c}
\hline \multicolumn{1}{c|}{ Produto } & $\begin{array}{c}\text { Concentração de cumarina } \\
(\mathrm{mg} / \mathrm{ml})\end{array}$ \\
\hline Xarope de guaco feito à quente & 0,0514 \\
Xarope de guaco feito à frio & 0,0261 \\
\hline
\end{tabular}

Tendo sido determinado que a maior eficiência da extração ocorre com a mistura hidroalcoólica a 70\%, procurou-se determinar se a melhor matéria-prima para se preparar a tintura seria a partir diretamente da planta fresca, da planta seca em temperatura ambiente ou se a partir da planta seca em estufa com circulação de ar.
O material vegetal foi dividido em três alíquotas, das quais uma foi extraída fresca, a outra após secagem à temperatura ambiente e a terceira após secagem na estufa a $40{ }^{\circ} \mathrm{C}$ por 48 hs. Os resultados estão apresentados na Tabela 2.

\section{Determinação da melhor forma de estocagem}

Tendo sido determinado que as melhores condições de extração sejam obtidas com a mistura hidroalcoólica a $70 \%$ e com a droga seca em estufa a $40{ }^{\circ} \mathrm{C}$ por 48 horas, procurou-se determinar a maneira mais adequada de estocar a droga. O material vegetal foi dividido em 3 alíquotas, sendo a primeira estocada na forma íntegra, a segunda previamente rasurada e a terceira convertida em tintura e nesta forma armazenada. Análises quantitativas dessas 3 amostras foram realizadas mensalmente. Os resultados obtidos estão apresentados na Tabela 3.

\section{Preparação da forma farmacêutica final}

As experiências anteriores indicaram as melhores condições de extração, secagem e estocagem. Partindo da tintura preparada nestas condições foram elaboradas amostras de xarope de guaco, adicionando-se tintura ao xarope à quente e ao xarope à frio. Esses xaropes foram analisados para quantificação de seu teor em princípio ativo. Os resultados obtidos estão apresentados na Tabela 4.

\section{DISCUSSÃO}

Através dos estudos realizados, diversas informações visando o desenvolvimento de um produto de qualidade à base de guaco foram obtidas. Para se desenvolver o processo tecnológico, utilizouse a substância cumarina como marcador, por ser responsável, pelo menos em parte, pela atividade do produto (Leite et al., 1992; Soares et al., 1996; Leal et al., 1996). Otimização do processo extrativo através da análise de tinturas preparadas com diversas alcoolaturas mostrou que uma mistura hidroalcoólica a $70 \%$ é capaz de produzir tintura com maior teor em cumarina. Utililizando essa mistura hidroalcoólica, foram realizados estudos para definir se a tintura deveria ser preparada a partir da planta fresca, da planta seca em estufa ou da planta seca à temperatura ambiente, para determinar o que deveria ser utilizado como matéria-prima na produção de tinturas. Os resultados obtidos mostraram que a tintura preparada com planta seca em estufa à 40 ${ }^{\circ} \mathrm{C}$ por 48 hs apresentou maiores teores em cumarina do que a preparada com planta fresca, que por sua vez apresentou os mesmos teores da tintura preparada com planta seca à temperatura ambiente. A melhor forma de estabilizar o material vegetal mostrou ser submetê-lo à secagem em estufa e preparar a tintura imediatamente, já que a estocagem tanto da planta inteira quanto da planta 
rasurada mostrou um decaimento acentuado no teor de princípio ativo. Preparação da forma farmacêutica final mostrou que a adição da tintura de guaco à quente ao xarope resulta no produto com maior teor em cumarina do que o obtido com a adição da tintura no xarope à frio.

Apesar de a cumarina ser uma substância volátil, foi notada a elevação de seu teor quando o processo envolveu manipulações que permitiram a elevação da temperatura da matéria-prima, como secagem da planta em estufa, moagem e preparação do xarope à quente. Esse aparente paradoxo já foi relatado na literatura para o Melilotus officinalis, sendo o melilotosídeo (Bruneton, 1993), um glicosídeo do ácido o-hidroxicinâmico se hidroliza facilmente, conduzindo por lactonização à formação da cumarina. A Mikania glomerata deve conter também um precursor, talvez o próprio ácido o-hidroxicinâmico, cuja presença nessa planta já foi relatada (Veneziani, 1997) que sob estas condições, se transforma em cumarina, aumentando assim o seu teor.

Como conclusão final, esse trabalhou mostrou que para se obter um fitoterápico de qualidade, com maior teor em princípio ativo, a planta Mikania glomerata fresca, deve ser seca em estufa com circulação de ar à $40{ }^{\circ} \mathrm{C}$ por $48 \mathrm{hs}$, transformada imediatamente após a secagem em tintura utilizando-se para sua extração uma mistura hidroalcoólica a 70\% e o xarope de guaco deve ser preparado pela adição da tintura ao xarope simples à quente.

\section{REFERÊNCIA}

Agra MF, Silva KN, Basílio IJLD, França PF, Barbosa-Filho JM 2008. Survey of medicinal plants used in the region Northeast of Brazil. Rev Bras Farmacogn 18: 472-508.

Amaral RR, Arcenio-Neto F, Carvalho ES, Teixeira LA, Araújo GL, Sharapin N, Testa B, Gnerre C, Rocha L 2003. Avaliação da atividade IMAO e antibacteriana de extratos de Mikania glomerata Sprengel. Rev Bras Farmacogn 13: 24-27.

Brandão MGL, Cosenza GP, Moreira RA, Monte-Mor RLM 2006. Medicinal plants and other botanical products from the Brazilian Official Pharmacopoeia. Rev Bras Farmacogn 16: 408-420.

Brandão MGL, Zanetti NNS, Oliveira GRR, Goulart LO, Monte-Mor RLM 2008. Other medicinal plants and botanical products from the first edition of the Brazilian Official Pharmacopoeia. Rev Bras Farmacogn 18: 127-134.

Bruneton J 1993. Pharmacognosie Phytochimie Plantes Medicinales. Londres Tec. Doc.

Dias da Silva RA 1929. Pharmacopeia dos Estados Unidos do Brasil. $1^{\text {a }}$ Ed., Companhia Editora Nacional.

Duarte MCT, Figueira GM, Pereira B, Magalhães PM, Delarmelina C 2004. Atividade antimicrobina de extratos hidroalcoólicos de espécies da coleção de plantas medicinais CPQBA/UNICAMP. Rev Bras Farmacogn 14 (Supl. 1): 6-8.

Falcão HS, Lima IO, Santos VL, Dantas HF, Diniz MFFM, Barbosa-Filho JM, Batista LM 2005. Review of the plants with anti-inflammatory activity studied in
Brazil. Rev Bras Farmacogn 15: 381-391.

Fierro IM, Silva AC, Lopes CD, Moura RS, Barja-Fidalgo C 1999. Studies on the anti-allergic activity of Mikania glomerata. J Ethnopharmacol 66: 19-24.

Leal LKAM, Matos FJA, Viana GSB 1996. Atividade broncodilatadora do extrato hidroalcoólico e da cumarina de Torresea cearensis Fr. All. (cumaru). Abstract F-128, XIV Simpósio de Plantas Medicinais do Brasil.

Leite MGR, Silva MAM, Lino CS, Viana GSB, Matos FJA 1992. Atividade broncodilatadora em Mikania glomerata, Justicia pectoralis e Torresca cearensis. Abstract 021, XII Simpósio de Plantas Medicinais do Brasil.

Pessini GL, Holetz FB, Sanches NR, Cortez DAG, Dias-Filho BP, Nakamura CV 2003. Avaliação da atividade antibacteriana e antifúngica de extratos de plantas utilizados na medicina popular. Rev Bras Farmacogn 13 (Supl. 1): 21-24.

Ruppelt BM, Pereira EF, Gonçalves LC, Pereira NA 1991. Pharmacological screening of plants recommended by folk medicine as anti-snake venon. I. Analgesic and anti-inflammatory activity. Mem Inst Oswaldo Cruz 86: 203-205.

Salgado HRN, Roncari AFF, Moreira RRD 2005. Antidiarrhoeal effects of Mikania glomerata Spreng. (Asteraceae) leaf extract in mice. Rev Bras Farmacogn 15: 205208.

Santos TC, Cabral LM, Tomassini TCB 1996. Contribuição para o estudo de Mikania glomerata Sprengel. Abstract Q-034, XIV Simpósio de Plantas Medicinais do Brasil.

Santos CR, Arcenio F, Carvalho ES, Lúcio EMRA, Araújo GL, Teixeira LA, Sharapin N, Rocha L 2003. Otimização do processo de extração de própolis através da verificação da atividade antimicrobiana. Rev Bras Farmacogn 13 (Supl. 1): 71-74.

Silva MIG, Gondim APS, Nunes IFS, Sousa FCF 2006. Utilização de fitoterápicos nas unidades básicas de atenção à saúde da família no município de Maracanaú (CE). Rev Bras Farmacogn 16: 455-462.

Soares AKA, Carmo GC, Quental DP, Nascimento DF, Bezerra FAF, Moraes MO, Moraes MEA 2006. Avaliação da segurança clínica de um fitoterápico contendo Mikania glomerata, Grindelia robusta, Copaifera officinalis, Myroxylon toluifera, Nasturtium officinale, própolis e mel em voluntários saudáveis. Rev Bras Farmacogn 16: 447-454.

Taleb-Contini SH, Santos PA, Veneziani RCS, Pereira AMS, França SC, Lopes NP, Oliveira DCR 2006. Differences in secondary metabolites from leaf extracts of Mikania glomerata Sprengel obtained by micropropagation and cuttings. Rev Bras Farmacogn 16 (Supl.): 596-598.

Teske M, Trentini AM, 1997 Compêndio de Fitoterapia Herbarium.

Veneziani RCS 1997. Estudo fitoquímico de Mikania glomerata Sprengel. Ribeirão Preto. Dissertação de Mestrado. Universidade de São Paulo - FFCLRP.

Vicentino ARR, Menezes FS 2007. Atividade antioxidante de tinturas vegetais, vendidas em farmácias com manipulação e indicadas para diversos tipos de doenças pela metodologia do DPPH. Rev Bras Farmacogn 17: 384-387. 